\title{
PENGARUH DISIPLIN KERJA DAN BUDAYA ORGANISASI TERHADAP KINERJA PEGAWAI NEGERI SIPIL PADA KANTOR KECAMATAN KELAPA GADING DI JAKARTA UTARA
}

\section{EFFECT OF DISCIPLINE WORKING AND CULTURAL ORGANIZATION ON THE PERFORMANCE OF CIVIL SERVANTS IN OFFICE DISTRICT KELAPA GADING ON NORTH JAKARTA}

\author{
Raymundus I Wayan Ray \\ Dosen Program Studi Administrasi Publik \\ Fakultas Ilmu Sosial dan Ilmu Politik \\ Universitas 17 Agustus 1945 Jakarta \\ raymundus.ray@uta45jakarta.ac.id
}

\begin{abstract}
ABSTRAK
Penelitian ini bertujuan untuk mengetahui secara empiris tentang pengaruh disiplin kerja dan budaya organisasi terhadap kinerja PNS di Kantor Kecamatan Kelapa gading, Jakarta Utara. Variabel terikat dalam penelitian ini adalah kinerja PNS, sedangkan variabel independen dalam penelitian ini adalah disiplin kerja dan budaya organisasi. Metode yang digunakan adalah deskriptif kuantitatif dengan menggunakan data primer yang diperoleh dari hasil penyebaran kuissioner. Jumlah kuissioner yang dibagikan kepada 40 responden, yang merupakan PNS dari Kecamatan Kantor Kelapa Gading Jakarta Utara. Sebuah analisis parsial dari hasil penelitian membuktikan bahwa disiplin pengaruh pekerjaan terhadap kinerja PNS begitu pengaruh budaya organisasi terhadap kinerja urusan petugas sipil. Sedangkan hasil analisis secara simultan diperoleh bahwa semua tes berngaruh signifikan antara disiplin kerja dan budaya organisasi terhadap kinerja PNS.
\end{abstract}

\section{Kata kunci: Disiplin Kerja, Budaya Organisasi dan Kinerja Karyawan}

\begin{abstract}
This research aims to know empirically on the influence of the discipline of work and organisational culture against the performance of civil servants in the Office of the Sub-District of Kelapa gading in North Jakarta. The dependent variable in this study was the performance of civil servants, while the independent variable in this study is the discipline of work and organisational culture. The method used is descriptive quantitative by using primary data obtained from the results of the spread of kuissioner. The amount of kuissioner that was distributed to 40 respondents, who is a civil servant of the Subdistrict Office Kelapa Gading Jakarta Utara. A partial analysis of the research results prove that the discipline
\end{abstract}


of work influence on the performance of civil servants so does the organizational culture influence on performance of civil affairs clerk. Whereas the results of the analysis are simultaneously obtained that all significant berngaruh test between the discipline of work and organisational culture against the performance of civil servants.

\section{Keywords: Discipline of Work, Organizational Culture and Employee Performance}

\section{PENDAHULUAN}

Negara Indonesia sebagai Negara Kesatuan menganut azas desentralisasi dalam penyelenggaraan pemerintahan, dengan memberikan kesempatan dan keleluasaan kepada Daerah untuk menyelenggarakan Otonomi Daerah. Hal ini diwujudkan dalam pemberian otonomi kepada daerah. Secara hukum, otonomi yang diberikan kepada daerah diatur dalam TAP MPR RI Nomor XV/MPR/1998 tentang Penyelenggaraan Otonomi Daerah. Dalam penyelenggaraannya, Otonomi Daerah dilaksanakan dengan prinsip-prinsip demokrasi, peran serta masyarakat, pemerintahan dan keadilan serta memperhatikan potensi dan keanekaragaman Daerah.

Pelaksanaan TAP MPR Nomor XV/MPR/1998 lebih lanjut diwujudkan dengan penyempurnaan UU No. 22 Tahun 1999 menjadi UU No. 32 Tahun 2004 tentang Pemerintahan Daerah. Dalam Undang-undang ini pemberian kewenangan Otonomi kepada Daerah Kabupaten/Kota didasarkan kepada azas desentralisasi saja dalam wujud otonomi yang luas, nyata dan bertanggung jawab. Dalam kewenangan otonomi yang luas ini tercakup keleluasaan daerah untuk menyelenggarakan pemerintahan yang meliputi kewenangan bidang pemerintahan kecuali kewenangan di bidang politik luar negeri, pertahanan keamanan, peradilan, moneter data fiskal, serta kewenangan bidang lainnya yang akan ditetapkan dengan Peraturan Pemerintah. Disamping itu keleluasaan otonomi mencakup pula kewenangan yang utuh dan bulat dalam penyelenggaraan mulai dari perencanaan, pelaksanaan, pengawasan, pengendalian dan evaluasi.

Pemberian kewenangan pemerintahan yang luas kepada daerah membawa konsekuensi langsung berkurangnya kewenangan Pemerintah Pusat terhadap daerah dan penambahan tanggung jawab kepada daerah. Terjadinya penambahan wewenang membawa konsekuensi penambahan tugas kepada daerah. Untuk melaksanakan semua tugas itu kemudian dilakukan restrukturisasi kelembagaan. Sejalan dengan restrukturisasi yang dilakukan, dibutuhkan peningkatan kinerja pegawai agar dapat melaksanakan tugas yang ada sebaik 
mungkin. Untuk itu perlu diperhatikan sikap dasar pegawai terhadap diri-sendiri, kompetensi, pekerjaan saat ini serta gambaran mereka mengenai peluang yang bisa diraih dalam struktur organisasi yang baru. Namun tidak dapat dipungkiri juga bahwa perubahan struktur organisasi yang baru dapat mengakibatkan rendahnya kinerja yang dimiliki pegawai yang terlihat dari sering terjadinya keterlambatan dalam penyelesaian pekerjaan.

Organisasi merupakan sistem dan kegiatan manusia yang bekerja secara bersama. Sejalan dengan itu, organisasi dikatakan sebagai suatu koordinasi rasional kegiatan sejumlah orang untuk mencapai beberapa tujuan umum melalui pembagian pekerjaan dan fungsi melalui hirarki otoritas dan tanggungjawab.

Faktor budaya organisasi, ada keterkaitan hubungan antara budaya organisas dengan kinerja organisasi yang dapat dijelaskan dalam model diagnosis budaya organisasi Tiernay bahwa "semakin baik kualitas faktorfaktor yang terdapat dalam budaya organisasi makin baik kinerja organisasi tersebut" (Moelyono Djokosantoso, 2003:42). Pegawai yang sudah memahami keseluruhan nilai-nilai organisasi akan menjadikan nilai-nilai tersebut sebagai suatu kepribadian organisasi. Nilai dan keyakinan tersebut akan diwujudkan menjadi perilaku keseharian mereka dalam bekerja, sehingga akan menjadi kinerja individual. Didukung dengan sumber daya manusia yang ada, sistem dan teknologi, strategi organisasi yang baik, masing-masing kinerja individu yang baik akan menimbulkan kinerja organisasi yang baik pula.

Berdasarkan latar belakang masalah tersebut di atas, maka peneliti tertarik untuk melaksanakan penelitian tentang : "Pengaruh disiplin kerja dan budaya organisasi terhadap kinerja pegawai Negeri Sipil di Lingkungan Kantor Camat Kelapa Gading Jakarta Utara"

\section{KAJIAN TEORI}

\section{Disiplin Kerja}

Menurut Slamet (2007:216), disiplin adalah suatu proses yang dapat menumbuhkan perasaan seseorang untuk mempertahankan dan meningkatkan tujuan organisasi secara obyektif, melalui kepatuhannya menjalankan peraturan organisasi. Dengan indikator indikatornya menurut Rivai ( 2006 : 444) adalah sebagai berikut : Konsekuen, Konsisten, Taat aturan, dan Bertanggungjawab.

\section{Budaya Organisasi}

Tampubolon, (2008:190-191) mengatakan budaya organisasi adalah merupakan kumpulan persepsi secara umum dari seluruh karyawan /pegawai sebagai anggota organisasi. Dengan indikatorindikatornya adalah sebagai berikut : 1) Karyawan berorientasi pada hasil yang akan dicapai, 2) Karyawan 
berorientasi kepada semua kepentingan karyawan, 3) Karyawan agresif di dalam bekerja, dan 4) Karyawan menjaga dan mempertahankan stabilitas kerja.

\section{Kinerja Pegawai}

Menurut Rivai (2006 : 309), kinerja pegawai adalah perilaku nyata yang ditampilkan setiap pegawai sebagai prestasi kerja yang dihasilkan sesuai dengan perannya dalam perusahaan/organisasi. Sedangkan indikator kinerja pegawai menurut, (Dharma, 2009:103), yaitu : Memiliki pengetahuan kerja dan professional, Bisa bekerja sama secara tim, Memiliki inisiatif dalam bekerja, dan Mampu mengambil keputusan yang tepat.

\section{KERANGKA BERPIKIR}

Berdasarkan pemikiran di atas, maka dapat digambarkan sebuah kerangka berpikir sebagai berikut :

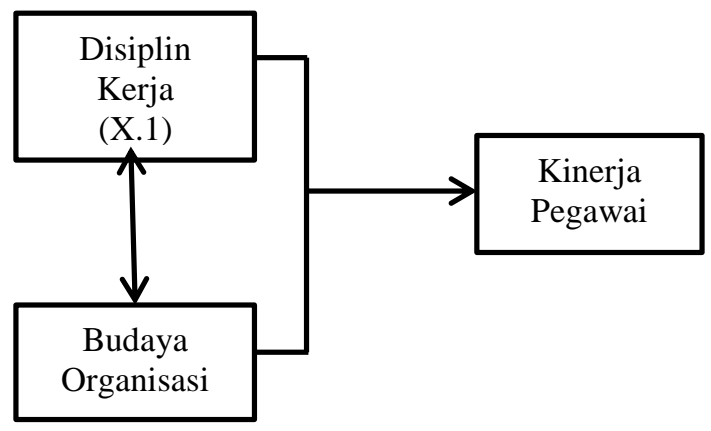

\section{HIPOTESIS}

Adapun hipotesis dalam penelitian ini adalah :

H.1 : Diduga disiplin kerja berpengaruh positif dan signifikan terhadap kinerja pegawai negeri sipil pada Kantor Kecamatan Kelapa Gading di Jakarta Utara.

H.2 : Diduga budaya organisasi berpengaruh positif dan signifikan terhadap kinerja pegawai negeri sipil pada Kantor Kecamatan Kelapa Gading di Jakarta Utara.

H.3: Diduga disiplin kerja dan budaya organisasi secara bersama-sama berpengaruh positif dan signifikan terhadap kinerja pegawai negeri sipil pada Kantor Kecamatan Kelapa Gading di Jakarta Utara.

\section{METODE PENELITIAN}

\section{Jenis Penelitian}

Penelitan ini adalah penelitian yang bersifat deskriptif kuantitatif yang bertujuan untuk mengetahui variabel-variabel apa saja yang dapat mempengaruhi kinerja pegawai negeri sipil.

\section{Jenis Data dan Teknik Pengumpulan Data}

Metode pengumpulan data menggunakan data primer yang dikumpulkan melalui penyebaran kuisioner. Data primer diperoleh melalui survey dengan cara mengisi kuissioner yang diberikan secara langsung kepada responden yang mau ditetliti. Dalam melaksanakan pengumpulan data dan informasi yang diperlukan sebagai dasar untuk penulisan penelitian, peneliti 
membuat kuisioner yang berisikan item-item pertanyaan dari masingmasing variabel yang akan diteliti. Jawaban responden akan diukur dengan menggunakan skala likert dalam 5 (lima) opsi, yaitu : Sangat Setuju $(\mathrm{SS})=5$, Setuju $(\mathrm{S})=4$, Netral $(\mathrm{N})=3$, Tidak Setuju $(\mathrm{TS})=2$, dan Sangat Tidak Setuju $($ STS $)=1$

\section{Populasi dan Sampel Penelitian}

Adapun populasi yang akan diteliti adalah seluruh pegawai negeri sipil dan semua kelurahan yang ada pada Kantor Kecamatan Kelapa Gading di Jakarta Utara yang berjumlah 60 orang. Dan besar sampel yang diambil adalah sebesar 60 orang dengan menggunakan rumus Sugiono. Sedangkan teknik untuk pengambilan sampel dalam penelitian ini menggunakan teknik Non-probability Sampling, adalah teknik pengambilan sampel yang tidak memberi peluang/kesempatan sama bagi setiap unsur atau anggota populasi untuk dipilih menjadi sampel. Dengan kata lain peneliti menggunakan teknik sampling jenuh, yakni penentuan sampel bila semua anggota populasi digunakan sebagai sampel.

\section{Variabel Penelitian}

Terdapat 3 (tiga) variabel dalam penelitian ini yang terdiri dari 2 (dua) variabel independen dan 1 (satu) variabel dependen.

Variabel Independen yang pertama dalam penelitian adalah Disiplin Kerja (X.1), yaitu suatu proses yang dapat menumbuhkan perasaan seseorang untuk mempertahankan dan meningkatkan tujuan organisasi secara obyektif, melalui kepatuhannya menjalankan peraturan organisasi.

Variabel independen yang kedua dalam penelitian ini adlah Budaya Organisasi ( X.2 ), yaitu merupakan kumpulan persepsi secara umum dari seluruh karyawan sebagai anggota organisasi.

Variabel Dependen dalam penelitian ini adalah Kenerja Pegawai Negeri Sipil (Y), yaitu hasil kerja secara kualitas dan kuantitas yang dicapai oleh seorang pegawai negeri sipil dalam melaksanakan tugasnya yang sesuai dengan tanggungjawab yang diberikan kepadanya.

\section{Teknik Analisis Data}

Untuk uji coba instrument dalam penelitian menggunakan Uji Validitas dan Reliabilitas. Validitas adalah ketepatan alat ukur/instrument yang dipergunakan dalam penelitian. Sedangkan Reliabilitas adalah konsitensi alat ukur/instrumen yang dipakai dalam penelitian. Rumus yang digunakan untuk menguji validitas adalah rumus korelasi product moment dari Pearson yang dinyatakan sebagai berikut :

$$
r x y=\frac{N\left(\sum x y\right)-\left(\sum x\right)\left(\sum y\right)}{\left.\sqrt{\left\{N\left(\Sigma x^{2}\right)-(\Sigma x)^{2}\right)\left(N\left(\Sigma y^{2}\right)-(\Sigma y)^{2}\right.}\right\}}
$$

Keterangan :

rxy : Koefisien Korelasi 
$\sum \mathrm{x} \quad$ : Jumlah Skor Variabel $\mathrm{x}$

$\sum \mathrm{y} \quad$ : Jumlah Skor Variabel y

$\sum \mathrm{x}^{2}$ : Jumlah Kuadrat Skor Variabel x

$\sum \mathrm{y}^{2}$ : Jumlah Kuadrat Skor

Variabel y

Exy : Jumlah Hasil Kali Skor Variabel $\mathrm{x}$ dan $\mathrm{y}$

$\mathrm{N}$ : Jumlah Responden

Kesimpulan :

Jika $\mathrm{r}_{\text {hitung }}>\mathrm{r}$ tabel, maka instrument itu mempunyai vaiditas yang tinggi

Jika $\mathrm{r}_{\text {hitung }}<\mathrm{r}_{\text {table, maka instrument itu }}$ untuk faktor tetentu tidak valid

Untuk menentukan reliabel atau tidak instrumen variabel independen, maka dilakukan uji reliabilitas dengan menggunakan rumus Alpha Cronchhbach sebagai berikut :

$$
r_{11}=\left[\frac{k}{k-1}\right]\left[1-\sum \frac{\propto b^{2}}{\propto 1^{2}}\right]
$$

Keterangan :

$$
\begin{array}{ll}
\mathrm{r}_{11} & : \text { Reliabilitas instrument } \\
\mathrm{k} & : \text { Banyaknya butir } \\
& \text { pertanyaan atau soal } \\
\sum \propto b^{2} & : \text { Jumlah varians butir } \\
\propto t^{2} & : \text { Varians total }
\end{array}
$$

\section{HASIL DAN PEMBAHASAN}

Berdasarkan hasil penelitian dan pengolahan data pengujian hipotesis secara parsial dan silmultan, maka dapat dilihat pada

\begin{tabular}{|c|c|c|c|c|c|c|}
\hline \multirow{2}{*}{\multicolumn{2}{|c|}{ Model }} & \multicolumn{2}{|c|}{$\begin{array}{l}\text { Unstandar } \\
\text { dized } \\
\text { Coefficient } \\
\text { s }\end{array}$} & $\begin{array}{l}\text { Standa } \\
\text { rdized } \\
\text { Coeffic } \\
\text { ients }\end{array}$ & \multirow[t]{2}{*}{$\mathrm{t}$} & \multirow[t]{2}{*}{$\begin{array}{l}\mathrm{Si} \\
\mathrm{g} .\end{array}$} \\
\hline & & B & $\begin{array}{l}\text { Std } \\
\text { Er } \\
\text { ror }\end{array}$ & Beta & & \\
\hline \multirow[t]{2}{*}{1} & $\begin{array}{l}\text { (Cons } \\
\tan t)\end{array}$ & $\begin{array}{l}12.6 \\
13 \\
\end{array}$ & $\begin{array}{l}3.2 \\
64\end{array}$ & & $\begin{array}{l}3.8 \\
64\end{array}$ & $\begin{array}{l}.0 \\
00\end{array}$ \\
\hline & $\begin{array}{l}\text { Disip } \\
\text { lin } \\
\text { Kerja }\end{array}$ & .874 & $\begin{array}{l}.10 \\
4\end{array}$ & .739 & $\begin{array}{l}8.3 \\
62\end{array}$ & $\begin{array}{l}.0 \\
00\end{array}$ \\
\hline \multicolumn{2}{|c|}{$\begin{array}{l}\text { Dependent } \\
\text { Negeri Sipil }\end{array}$} & \multicolumn{2}{|c|}{ Variable: } & Kinerja & \multicolumn{2}{|c|}{ Pegawai } \\
\hline
\end{tabular}
table di bawah ini :
Tabel 1. Uji Hipotesis Parameter Individual Displin Kerja $\left(\mathrm{X}_{1}\right)$ Terhadap Kinerja Pegawai Negeri Sipil (Y)

\begin{tabular}{|c|c|c|c|c|c|c|}
\hline \multirow{2}{*}{\multicolumn{2}{|c|}{ Model }} & \multicolumn{2}{|c|}{$\begin{array}{l}\text { Unstandard } \\
\text { ized } \\
\text { Coefficients }\end{array}$} & $\begin{array}{l}\text { Standar } \\
\text { dized } \\
\text { Coeffici } \\
\text { ents }\end{array}$ & \multirow[t]{2}{*}{$\mathrm{t}$} & \multirow[t]{2}{*}{$\begin{array}{l}\mathrm{Si} \\
\text { g. }\end{array}$} \\
\hline & & $\mathrm{B}$ & $\begin{array}{l}\text { Std. } \\
\text { Erro } \\
r\end{array}$ & Beta & & \\
\hline \multirow[t]{2}{*}{1} & $\begin{array}{l}\text { (Const } \\
\text { ant) }\end{array}$ & $\begin{array}{l}9.7 \\
58\end{array}$ & $\begin{array}{l}2.51 \\
7\end{array}$ & & $\begin{array}{l}3.8 \\
76\end{array}$ & $\begin{array}{l}.0 \\
00\end{array}$ \\
\hline & $\begin{array}{l}\text { Buday } \\
\text { a } \\
\text { Organ } \\
\text { isasi } \\
\end{array}$ & $\begin{array}{l}.96 \\
3\end{array}$ & .080 & .844 & $\begin{array}{l}11 . \\
990\end{array}$ & $\begin{array}{l}.0 \\
00\end{array}$ \\
\hline \multicolumn{2}{|c|}{$\begin{array}{l}\text { Dependent } \\
\text { Negeri Sipil }\end{array}$} & \multicolumn{2}{|c|}{ Variable: } & Kinerja & \multicolumn{2}{|c|}{ Pegawai } \\
\hline
\end{tabular}

Tabel 2. Uji Hipotesis Parameter Individual Variabel Budaya Organisasi $\left(\mathrm{X}_{2}\right)$ Terhadap Kinerja Pegawai Negeri Sipil (Y)

Tabel 3. Uji Hipotesis Berganda Disiplin Kerja dan Budaya Organisasi Terhadap Kinerja Pegawai Negeri Sipil. 


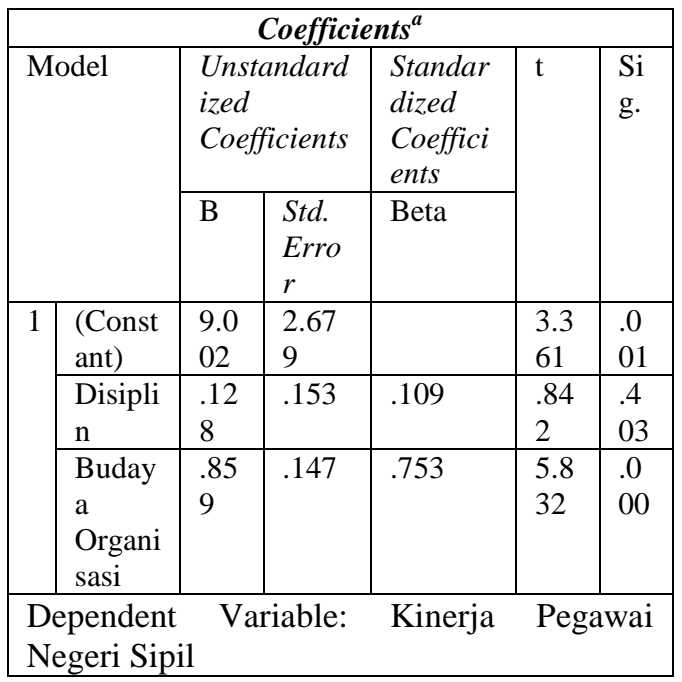

\begin{tabular}{|c|c|c|c|c|c|c|}
\hline \multicolumn{7}{|c|}{$A N O V A^{b}$} \\
\hline \multicolumn{2}{|c|}{ Model } & $\begin{array}{l}\text { Sum of } \\
\text { Squares }\end{array}$ & $d f$ & $\begin{array}{l}\text { Mean } \\
\text { Squar } \\
e\end{array}$ & $F$ & Sig. \\
\hline 1 & Regression & 685.435 & 2 & $\begin{array}{l}342.7 \\
17\end{array}$ & $\begin{array}{l}71 . \\
868\end{array}$ & $\begin{array}{l}.00 \\
0^{\mathrm{a}}\end{array}$ \\
\hline & Residual & 271.815 & 57 & 4.769 & & \\
\hline & Total & 957.250 & 59 & & & \\
\hline
\end{tabular}

a. Predictors: (Constant), Disiplin Kerja, Budaya Organisasi

b. Dependent Variable : Kinerja Pegawai Negeri Sipil

Tabel 4. Hasil Uji Koefisien Determinasi

\begin{tabular}{|c|c|c|c|c|}
\hline \multicolumn{5}{|c|}{ Model Summary } \\
\hline $\begin{array}{l}\text { Mod } \\
\text { el }\end{array}$ & $\mathrm{R}$ & $\begin{array}{l}R \\
\text { Squa } \\
\text { re }\end{array}$ & $\begin{array}{c}\text { Adjust } \\
\text { ed } R \\
\text { Squa } \\
\text { re }\end{array}$ & $\begin{array}{l}\text { Std. } \\
\text { Error } \\
\text { of the } \\
\text { Estim } \\
\text { ate }\end{array}$ \\
\hline 1 & .84 & .716 & .706 & 2.1837 \\
\hline
\end{tabular}

\begin{tabular}{|l|l|l|l|}
\hline & $6^{\mathrm{a}}$ & & 3 \\
\hline a. Predictors: (Constant), Disiplin
\end{tabular}

Kerja X1, Budaya Organisasi X2.

Berdasarkan tabel di atas, maka hasil pengujian hipotesis adalah sebagai berikut :

\section{Pengujian Hipotesis Pertama}

(H.1). Hasil pengujian hipotesis pertama ditemukan bukti secara empiris bahwa secara parsial, Disiplin Kerja mempunyai pengaruh yang signifikan

terhadap Kinerja Pegawai Negeri Sipil pada Kantor Kecamatan Kelapa Gading di Jakarta Utara. Jadi arah pengaruh yang diberikan adalah positif, yang berarti pengaruhnya searah dan signifikan. Hal ini berarti hipotesis pertama diterima.

\section{Pengujian Hipotesis Kedua (H.2).} Hasil pengujian hipotesis kedua ditemukan bukti secara empiris bahwa secara parsial, Budaya Organisasi mempunyai pengaruh yang signifikan terhadap Kinerja Pegawai Negeri Sipil pada Kantor Kecamatan Kelapa Gading di Jakarta Utara. Jadi arah pengaruh yang diberikan adalah positif, yang berarti pengaruhnya searah dan signifikan. Hal ini berarti hipotesis kedua diterima

\section{Pengujian Hipotesis Ketiga (H.3).}

Hasil pengujian hipotesis ketiga ditemukan bukti secara empiris bahwa secara simultan Disiplin Kerja, Budaya Organisasi 
mempunyai pengaruh yang signifikan terhadap Kinerja Pegawai Negeri Sipil pada Kantor Kecamatan Kelapa Gading di Jakarta Utara. Jadi arah pengaruh yang diberikan adalah positif, yang berarti pengaruhnya searah dan signifikan. Hal ini berarti hipotesis ketiga diterima.

\section{PENUTUP}

\section{a. Kesimpulan}

Berdasarkan dari hasil pembahasan tersebut di atas, maka penulis dapat menarik kesimpulan sebagai berikut : 1) Berdasarkan dari hasil analisis yang penulis lakukan diketahui secara empiris bahwa Disiplin Kerja berngaruh positif dan signifikan terhadap Kinerja Pegawai Negeri Sipil, hal tersebut terbukti dari hasil uji hipotesis yang diperoleh hasilnya nilai $\mathrm{t}_{\text {hitung }}=8,362>\mathrm{t}_{\text {tabel }}=$ 1,6747 atau 0,000 < 0,05 maka Ho ditolak dan $\mathrm{Ha}$ diterima, artinya secara parsial maka hipotesis pertama dalam penelitian ini adalah disiplin kerja berpengaruh positif dan signifikan terhadap kinerja pegawai negeri sipil. 2) Berdasarkan hasil analisis yang telah dilakukan diperoleh hasil bahwa budaya organisasi secara parsial berpengaruh positif dan signifikan terhadap kinerja pegawai negeri sipil, hal ini dapat dilihat hasil nilai $t_{\text {hitung }}$ sebesar 11,990 sedangkan nilai $t_{\text {tabel }}$ pada tingkat signifikan 95\% $(\alpha=0,05)$ sebesar 1,6747 maka $t_{\text {hitung }}>t_{\text {tabel }}(\alpha=$ $0,05)$, hasil analisis tersebut signifikan. Hal ini berarti hipotesis kedua yang diajukan dapat diterima karena variabel budaya organisasi berpengaruh positif dan signifikan terhadap kinerja pegawai negeri sipil di dalam regresi.

3) Berdasarkan hasil analisis uji hipotesis secara silmultan bahwa disiplin kerja dan budaya organisasi berngaruh positif dan signifikan terhadap kinerja pegawai negeri sipil. Hal ini terbukti dari hasil perhitungan bahwa nilai koefisien regresi untuk variabel disiplin kerja sebesar 0,128 sedangkan nilai koefisien regresi untuk variabel budaya organisasi sebesar 0,859 dan nilai konstanta sebesar 9,002 hal ini menunjukkan bahwa apabila variabel disiplin kerja dan budaya organisasi tidak ada $\left(\mathrm{X}_{1}\right.$ dan $\left.\mathrm{X}_{2}=0\right)$ maka variabel kinerja pegawai negeri sipil sebesar 9,002, hal ini secara simultan produktivitas kerja dipengeruhi oleh variabel pendidikan dan pelatihan sebesar 0,128 dan variabel kinerja pegawai negeri sipil sebesar 0,859 . Setelah nilai koefisien regresi dan nilai konstanta diketahui maka model regresi linier berganda adalah $\mathrm{Y}=$ $9.002+0,128 X_{1}+859 X_{2}$

Hasil pengujian hipotesis sebagai berikut: Hipotesis ketiga ( H.3) menyatakan bahwa disiplin kerja dan budaya organisasi berpengaruh positif terhadap kinerja pegawai negeri sipil, hal ini dapat dilihat hasil perhitungan nilai $F_{\text {hitung }}$ sebesar 71,858 sedangkan nilai $F_{\text {tabel }}$ pada tingkat signifikan 95\% ( $\alpha=$ 0,05) sebesar 3,15 maka dapat dikatakan bahwa nilai $\mathrm{F}_{\text {hitung }}>\mathrm{F}_{\text {tabel }}$ $(\alpha=0,05)$ dan hasil analisis tersebut signifikan 4. Dari hasil analisis 
statistik dengan menggunakan program SPSS 16.0 diperoleh nilai Adjusted R Square sebesar 0,706 hal ini berarti $70,6 \%$ kinerja pegawai negeri sipil dapat dijelaskan oleh variasi dari kedua variabel independen ( disiplin kerja dan budaya organisasi). Sedangkan sisanya $29,4 \%$ dijelaskan oleh faktorfaktor lain di luar penelitian ini.

Keterbatasan Penelitian, Penelitian ini juga masih memiliki keterbatasan - keterbatasan. Dengan keterbatasan ini, diharapkan dapat dilakukan perbaikan untuk penelitian yang akan datang. Adapun keterbatasan dalam penelitian ini antara lain:1. Jumlah responden belum bisa menggambarkan kondisi riil yang sesungguhnya.2.Hasil pengisian kuesioner terutama untuk jenis pertanyaan terbuka masih terdapat beberapa yang berisi jawaban kosong, hal ini dikarenakan aktivitas beberapa responden yang cukup padat dan jumlah pertanyaan terbuka yang cukup banyak, dimana terletak di masing-masing indikator sehingga tidak memungkinkan responden mengisi semua pertanyaan terbuka yang ada.3.Adanya keterbatasan penelitian dengan menggunakan kuesioner yaitu terkadang jawaban yang diberikan oleh responden tidak menunjukkan keadaan sesungguhnya.

\section{a. Saran}

Memperhatikan adanya beberapa keterbatasan seperti yang telah disampaikan maka bagi penelitian selanjutnya perlu memperhatikan beberapa saran berikut ini: 1.Dari hasil penelitian yang dilakukan, variabel yang paling dominan dalam mempengaruhi kinerja pegawai negeri sipil yaitu disiplin kerja. 2.Dukungan dari kepemimpinan Camat maupun Lurah sangat mempengaruhi kinerja pegawai negeri sipil yang dirasakan oleh pegawai. Dukungan lebih yang diberikan oleh pimpinan Camat maupun Lurah dapat membuat merasa nyaman dalam bekerja dan pegawai diberi tanggungjawab lebih sehingga pegawai dapat memaksimalkan kemampuannya untuk bekerja lebih baik.3. Untuk penelitian selanjutnya, disarankan untuk menambah variabel bebas yang lain seperti pengetahuan, motivasi, dan lain sebagainya. Melakukan penyempurnaan kuesioner ini, serta melakukan pemilihan waktu yang tepat ketika menyebar kuesioner. Hal ini dikarenakan sebagian besar kuesioner dalam penelitian ini yang tidak kembali dikarenakan para calon responden tidak punya cukup waktu.

\section{DAFTAR PUSTAKA}

Hersey, Paul and Blanchard, 1982. Management of Organizational behavior, utilizing human resources. 4th edition. Prentice-hall, Inc. Agus Dharma (penerjemah). Manajemen Perilaku Organisasi. Pendayagunaan Sumber Daya Manusia. Edisi ke 4. Jakarta. Erlangga. 
1992. Manajemen Perilaku

Organisasi Pendayagunaan SDM, Cetakan Ketiga, Alih Bahasa Agus Dharma. Erlangga, Jakarta.

Irawanto, Dodi Wirawan, 2013. Kepemimpinan Esensi Dan Realitas, Bayumedia Publishing, 2013, Malang.

Kartono, Kartini, 2013, Pemimpin dan Kepemimpinan: Apakah Kepemimpinan Abnormal itu?, Badan Penerbit Rajawali Press, 2013, Jakarta.

Mangkunegara, Prabu, 2006. Evaluasi Kinerja SDM. Jakarta : Refika Aditama.

Prabowo, Lindu, 2012. Analisis Stres Kerja dan Kepuasan Kerja terhadap Produktivitas Karyawan Wanita pada PR Dollar Prima. Skripsi. Program Studi Manajemen, Universitas Brawijaya.

Rivai,Veithzal dan Deddy Mulyadi, 2009. Kepemimpinan Dan Perilaku Organisasi Edisi Ketiga, Jakarta, PT. Rajagrafindo persada.

Rivai, Veithzal, 2011. Performance Appraisal. Badan penerbit : Rajawali Pers, Jakarta.

Robbins, Stephen P, 1996. Perilaku Organisasi, Konsep,
Kontroversi dan Aplikasi. Alih Bahasa: Hadyana Pujaatmaka. Edisi keenam. Jakarta : PT. Nhuana Ilmu Populer.

2006. Perilaku Organisasi, Edisi Kesepuluh. PT. Indeks, Jakarta.

, 2008. Perilaku Organisasi. Jakarta : Salemba Empat.

Schein, Edgar, 1991. Organizational culture and Leadership. Oxford Jossey - Bass Publisher. San Fransisco.

Sugiyono, 2008. Metode Penelitian Bisnis. Alfabeta, Bandung.

........, 2010. Metode Penelitian Bisnis. Alfabeta, Bandung.

........., 2012. Metode Penelitian Bisnis. Alfabeta, Bandung.

Thoha, Miftah, 2007. Kepemimpinan dalam Manajemen. Jakarta : PT. Raja Grafindo Persada

Umar, Husein, 2010. Desain Penelitian MSDM dan Perilaku Karyawan Paradigma Positivistik dan Berbasis Pemecahan Masalah. Rajawali Pers, Jakarta.

Wirawan, 2007. Budaya dan Iklim Organisasi. Salemba Empat, Jakarta 